\title{
UTILIZATION OF PRESERVED BAMBOO IN SRI LANKA
}

\author{
M B Herath and Shanthi Illangasinghe \\ CISIR, Colombo
}

Bamboo is one of the oldest materials used by mankind to increase comfort and upliftment of human life. It is best put to use in situation where its natural properties are emphasized. The strength of bamboo culms, their straightness smoothness, lightness, cylindric structure, abundance and shorter period in which they attain maturity make them suitable for a wide variety of purposes. Bamboo has excellent properties but its natural resistance to decay is low. Chemical preservation using preservatives which have good diffusion properties, improves, the durability of bamboo structures.

Fourteen species of bamboo have been reported growing in Sri Lanka, and only five of them are used. They are widely used, for the craft industry and scaffoldings.

World demand for handicrafts made of bamboo has increased considerably the development of cottage industries based on preserved bamboo will directly benefit poor rural people. The whole biomass of the tree can be utilized.

Bamboo has several characteristics that make it a suitable and economical building material for building construction, as well as for the scaffolding that facilitates the same. In place of steel, bamboo has been considered as a reinforcement factor for concrete.

The major problem is the shortage of the raw material of bamboo in utilization in Sri Lanka. Wastage of bamboo can be minimized by introducing the preservation methods. People must be made aware of the value of bamboo in order to encourage their supportive participation in development, conservation and usage aspects. Bamboo products can be promoted as a substitute to plastic and polythene goods by highlighting their environment friendly qualities.

Proceedings of the Third Annual Forestry Symposium 1997, of the Department of Forestry and Environmental Science, University of Sri Jayewardenepura, Sri Lanka 